\title{
Capacidad de infección de Beauveria bassiana (nativa) sobre el complejo de chinches del cultivo de Chenopodium Quinoa en la irrigación Majes 2018
}

Infection of capacity of Beauveria bassiana (nativa) on the chinches complex of the crop of Chenopodium Quinoa in the irrigation Majes 2018

Dina Beatriz Mamani Gutierrez y Celia Martha Pinto Manrique.

Autoridad Autónoma de Majes (Autodema), Irrigación Majes, Distrito de Caylloma, Provincia y Departamento de Arequipa.

\section{INFORMACIÓN}

\section{Historia del Artículo}

Recepción: 03/03/2019

Revisión: 25/05/2019

Aceptación: 27/06/2019

\section{Palabras Clave}

Capacidad de infección, Beauveria bassiana (nativa), Nysius sp., Liorhysus sp. estados inmaduros y adultos.

\section{Key Words}

Infection capacity, Beauveria bassiana (native), Nysius sp., Liorhysus sp., immature and adult states.

\section{DOI}

https://doi.org/10.35286/veritas. v20i1.232

\begin{abstract}
RESUMEN
El presente trabajo de investigación se desarrolló en los campo de investigación (CRA) y en el laboratorio de la AUTODEMA en la Irrigación de Majes en el año 2018, a fin de evaluar la capacidad de infección de Beauveria bassiana (nativa) como controlador microbiológico de los chinches del cultivo de quinua en la Irrigación de Majes; siendo el principal objetivo de la investigación. A fin de realizar esta experimentación se obtuvo conidias de Beauveria bassiana (nativa) de chinches provenientes de campos de quinua de la Irrigación Majes; realizando el aislamiento directo del hongo hasta la producción artesanal de éste. Para evaluar la capacidad de infección del hongo en mención se realizó una aplicación de solución con el entomopatógeno, para lo cual después de la aplicación se realizaron muestreos de insectos por un periodo de 7 días posteriores a la aplicación. Dichos especímenes fueron puestos en cajas de crianza y posterior a su muerte se les coloco en cámara húmeda para observar si esto fueron infectados o no por Beauveria bassiana (nativa). Los resultados obtenidos indican que Nysius sp. es más susceptible que Liorhysus sp. a ser infectado por el entomopatógeno es estudio. Se observa que en estados inmaduros (ninfa) presentan una mayor patogenicidad, ya que, se obtuvo un $42.86 \%$ de mortalidad. A diferencia de los adultos donde se observa una mayor tolerancia a la infección de Beauveria bassiana (nativa), obteniéndose el $33.33 \%$ de mortalidad.
\end{abstract}

\begin{abstract}
The present research work was developed in the field of research (CRA) and in the laboratory of the AUTODEMA in Majes Irrigation in 2018, in order to evaluate the infection capacity of Beauveria bassiana (native) as microbiological controller of the bugs of quinoa cultivation in Majes Irrigation; being the main objective of the investigation. In order to carry out this experiment, conidia of Beauveria bassiana (native) were obtained from bed bugs from quinoa fields of the Majes Irrigation; making the direct isolation of the fungus until the artisanal production of this one. To evaluate the infection capacity of the fungus in question, a solution application was made with the entomopathogen, for which after the application, insect samplings were made for a period of 7 days after the application. These specimens were placed in nursery boxes and after their death they were placed in a humid chamber to see if they were infected or not by Beauveria bassiana (native). The results obtained indicate that Nysius sp. it is more susceptible than Liorhysus sp. to be infected by the entomopathogen is study. It is observed that in immature stages (nymph) have a greater pathogenicity, since, $42.86 \%$ mortality was obtained. Unlike adults where there is greater tolerance to infection of Beauveria bassiana (native), obtaining $33.33 \%$ mortality.
\end{abstract}

\section{INTRODUCCIÓN}

El control biológico consiste en la utilización de organismos vivos (enemigos naturales) introducidos $\mathrm{o}$ manipulados para mantener la población de otro organismo plaga bajo el nivel de daño económico.

Enestaoportunidadutilizamosel "controlmicrobiológico" que se basa en la utilización de microorganismos ya sea bacterias, virus, protozoarios, nematodos $u$ hongos para reducir y estabilizar las poblaciones de insectos plaga. Donde destacan los hongos entomopatógenos que son microorganismos capaces de infectar y provocar enfermedades en insectos causándoles la muerte. Por esto se

Correspondencia:

Dina Beatriz Mamani Gutierrez

dibemagu7@hotmail.com convierten en una herramienta con un gran potencial para el control de las plagas.

Los hongos entomopatógenos son organismos de importante valor ecológico al desempeñar funciones de regulación sobre insectos, quienes debido al mal manejo de pesticidas realizado por el humano para su control se han convertido en plagas incontrolables y resistentes, convirtiendo a los hongos entomopatógenos en una opción viable para la elaboración de bioplaguicidas que permitan el control de los mismos sin contaminación y deterioro del medio ambiente; no obstante, se debe tener en cuenta que el impacto en el ambiente puede ser negativo al controlar especies de insectos benéficas como es el caso de las abejas (Api mellifera), polinizadoras por excelencia en el ecosistema. El desarrollo de productos a base de hongos entomopatógenos debe involucrar investigación para determinar el nivel de interacción del hongo con su hospedero y con el medio ambiente, la concentración del 
producto y el método de formulación adecuado que permita llevar estos microorganismos a condiciones de campo para que desempeñen una función de buena capacidad reguladora de las plagas dentro del agroecosistema. (Delgado, P. A. M., Murcia-Ordoñez, B. 2011)

El ataque de los hongos entomopatógenos se asocia a una gran cantidad de insectos, los cuales son infectados preferentemente en los estadios inmaduros (ninfa o larva). La especificidad con la que atacan a los insectos plaga es bastante variable, ya que algunos tienen un amplio rango de hospederos, mientras que otros están restringidos a una especie de insecto. Entre los principales géneros de hongos entomopatógenos que se utilizan en la agricultura se encuentra Beauveria, Metarhizium, Paecilomyces, Verticillium y Trichoderma. .

El éxito de estos entomopatógenos está en función de la biología de los insectos plaga y del medio ambiente en que se encuentren para poder decidir cuál es la especie más adecuada y el momento oportuno para aplicarlo. Por lo general, estos hongos infectan a los insectos mediante la penetración de su cutícula, volviéndose con ello en una gran alternativa para el control de insectos chupadores.

No obstante, es fundamental propiciar las condiciones adecuadas de temperatura y humedad para lograr su propósito. Los hongos son parte fundamental del manejo integrado de plagas, debido a que atacan a los insectos en cualquier estado de desarrollo. (El mercurio)

\section{Materiales y métodos}

\section{Materiales}

Material biológico (adultos Nysius sp., adultos y ninfas de Nysius sp. y Liorhysus sp), placas petri de vidrio y descartables, medio de cultivo (SDA y PDA), Tween, frascos elermeyer $500 \mathrm{ml}$., lámpara UV, aceite agrícola, frascos de vidrio de $600 \mathrm{ml}$, tapers, pisetas, asperjadores, algodón, silica gel, pinzas, espatulas, papel toalla, alcohol al $70 \%$, hipoclorito de sodio al $1 \%$, agua destilada, bolsas de polipropileno, arroz superior, incubadora, cámara de flujo laminar, estereoscopio, campo cultivo de quinua, colador, ablandador, bomba de mochila, plumones indelebles y cuaderno de apuntes.

\section{Metodología}

\section{Procedimiento de obtención o aislamiento directo del hongo}

Se recolectaron especímenes de campo (Nysius $\mathrm{sp}$ ) los cuales fueron desinfectados con hipoclorito de sodio al $0.05 \%$ durante 2 minutos luego se enjuagaron tres veces en agua destilada estéril y para eliminar el exceso de agua se colocaron en papel toalla estéril. Posteriormente los insectos desinfectados se pusieron en cámara húmeda las que se pusieron a incubar durante 6 días a temperatura ambiente. Una vez que se observó los insectos esporulados con Beauveria bassiana (nativa), se procedió a sembrar en hongo por puntura en placas petri con medio de cultivo SDA con antibiótico; se colocaron a incubar las placas preparadas durante 5 a 10 días a una temperatura de $25 \pm 2{ }^{\circ} \mathrm{C}$. Las cepas obtenidas se coservaron en silica Gel (color anaranjado).

\section{Preparación del medio o caldo de cultivo}

Se prepararon placas con medio PDA con antibiótico, donde se colocó cepas conservadas en silica gel, este material se colocó en incubación durante 7 días; una vez llenas las placas por el crecimiento del hongo Beauveria bassiana (nativa) con buena esporulación y libre de contaminación. Se le agregó $10 \mathrm{ml}$ de agua destilada estéril más Tween y con la ayuda de una espátula estéril, se raspó suavemente la superficie de la placa, para soltar las esporas o conidias, esta mezcla se juntó con $90 \mathrm{ml}$ de agua destilada estéril más Tween; todo esto fue colocado en un frasco elermeyer estéril a incubar por 48 horas a $25 \pm 2{ }^{\circ} \mathrm{C}$.

\section{Procedimiento de producción bolsas}

Se preparó el sustrato a base de $800 \mathrm{~g}$ de arroz y $200 \mathrm{ml}$ de agua, este fue colocado en bolsas de polipropileno; para la esterilización fueron puestas en autoclave $\left(121^{\mathrm{a}} \mathrm{C}, 15 \mathrm{Lb}\right.$ de presión) por 30 minutos. Las bolsas fueron engrapadas con previo doblez.

En un ambiente previamente esterilizado con luz UV se colocaron las bolsas y se procedió a descompactar el arroz, para que no se formen grumos.

Una vez frías las bolsas, se llevaron a la cámara de flujo laminar, se desinfectó el borde de cada bolsa con alcohol, se abrió cuidadosamente las bolsas; cada bolsa se inoculó con $25 \mathrm{ml}$ del caldo de cultivo agitado, Se cerró nuevamente la bolsa y se agitó para homogenizar el inóculo con el sustrato. Las bolsas inoculadas se llevaron a sala de germinación a temperatura de 24 a $28{ }^{\circ} \mathrm{C}$, incubándose en oscuridad los primeros 3 días para favorecer el desarrollo del micelio. Al finalizar el tercer día se encendió la luz de los cuartos de incubación. Al cuarto día de incubación, las bolsas fueron quebradas suavemente para favorecer la oxigenación de todo el sustrato y se dejaron por 11 días donde completaron la esporulación. Durante este tiempo se revisaron las bolsas diariamente, eliminando las presentaron contaminantes Figura 1.

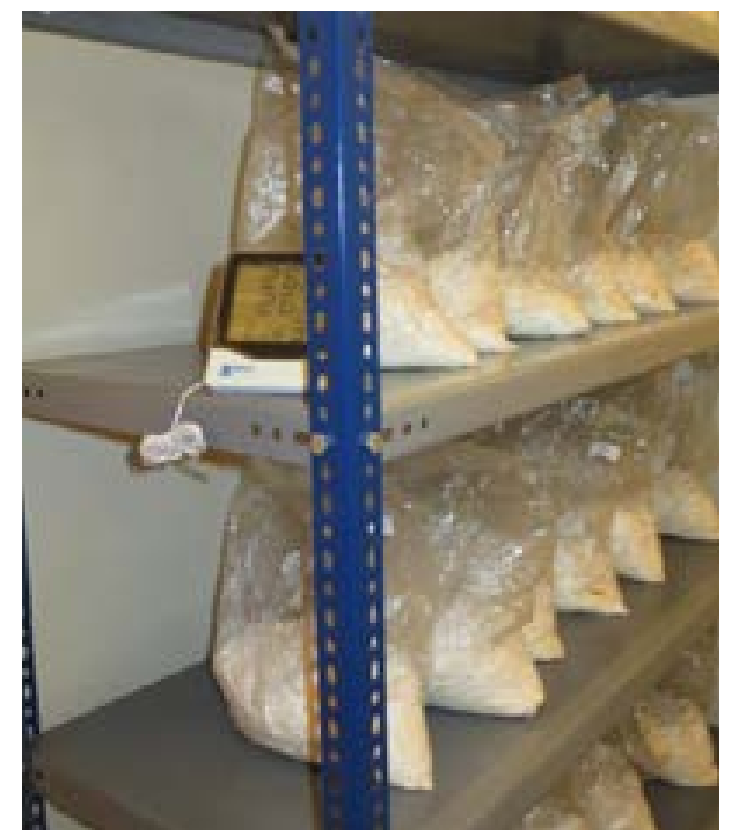

Fig. 1: Producción de hongos entomopatógenos 


\section{Preparación del producto a ser aplicado en campo}

Lo recomendado es 2 bolsas de 800 gr. por 200 lt. de agua, para nuestro ensayo se preparó 20 lt. de agua con 160 gr de hongo entomopatógeno. Se preparó el agua midiendo la dureza y la acidez para que los valores no sobrepasen 150 ppm y $7 \mathrm{pH}$. Se agregó $20 \mathrm{ml}$ de aceite agrícola en el hongo, se mezcló bien y se le agregó $20 \mathrm{ml}$ del agua preparada y se mezcló de tal manera que se suelten las conidias del arroz hasta crear una emulsión. Dicha emulsión se coló y se lavó bien hasta que el arroz quedó sin hongo.

Se dejó reposar la solución durante 6 horas para que las conidias se hidraten, luego se mezcló en la mochila de 20 lt. y se aplicó en un área de $100 \mathrm{~m}$, tratando de aplicar en los lugares donde se encontraban los chinches.

Dicha solución fue aplicada en campo y durante los 7 días posteriores se realizó la recolección (muestreos) de insectos; donde todos los especímenes capturados fueron criados en laboratorio y al cabo de 04 días (tiempo en que el que hongo tarda en colonizar) los individuos que se encontraron muertos, fueron puestos en cámara húmeda; para promover el crecimiento del hongo y verificar que la muerte ocurrió por acción del hongo, tomando en cuenta la presencia del micelio Figura 2 y 3.

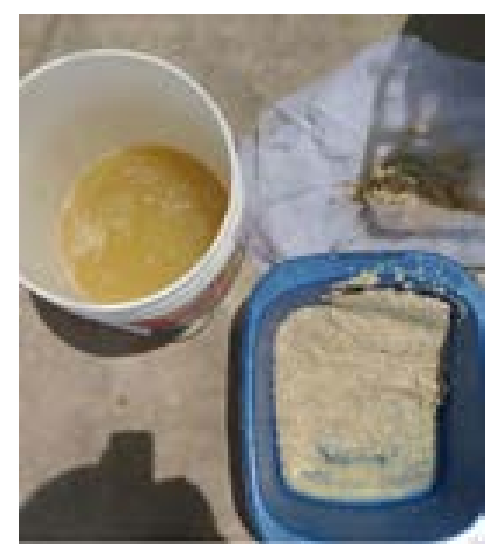

Fig. 2: Preparación del entomopatógeno para ser aplicado en campo

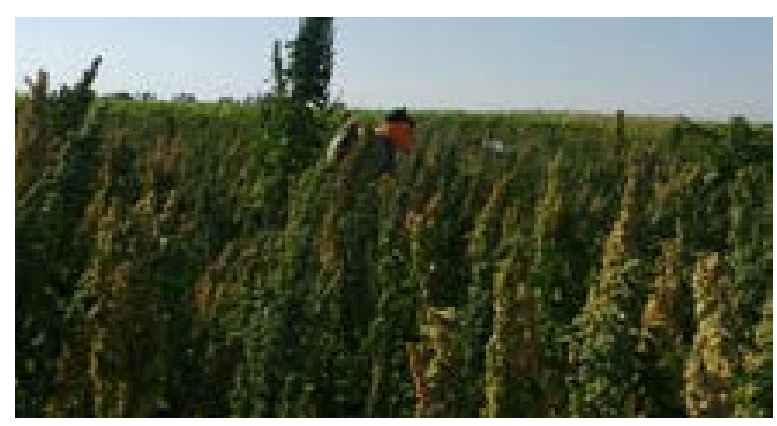

Fig. 3: Aplicación de entomopatógenos en campo de quinua

\section{RESULTADOS Y DISCUSIONES}

Se pudo observar que en campo existe mayor cantidad de especímenes adultos de Nysius sp. por ende se observa una mayor cantidad de dicha especie infectada por el hongo entomopatógeno aplicado (Tabla 1).

Tabla 1: Número total especímenes infectados por Beauveria bassiana (nativa)

\begin{tabular}{|c|c|c|c|c|c|c|c|c|}
\hline \multirow{3}{*}{$\begin{array}{l}\text { Días de } \\
\text { instalación } \\
\text { Cámara } \\
\text { Húmeda }\end{array}$} & \multicolumn{4}{|c|}{ Adultos } & \multicolumn{4}{|c|}{ Ninfas } \\
\hline & $\begin{array}{l}\text { individuos } \\
\text { expuestos }\end{array}$ & $\begin{array}{l}\text { individuos } \\
\text { colonizados }\end{array}$ & $\begin{array}{l}\text { individuos } \\
\text { expuestos }\end{array}$ & $\begin{array}{l}\text { individuos } \\
\text { colonizados }\end{array}$ & $\begin{array}{l}\text { individuos } \\
\text { expuestos }\end{array}$ & $\begin{array}{l}\text { individuos } \\
\text { colonizados }\end{array}$ & $\begin{array}{l}\text { individuos } \\
\text { expuestos }\end{array}$ & $\begin{array}{l}\text { individuos } \\
\text { colonizados }\end{array}$ \\
\hline & \multicolumn{2}{|c|}{ Nysius sp. } & \multicolumn{2}{|c|}{ Liorhysus sp } & \multicolumn{2}{|c|}{ Nysius sp. } & \multicolumn{2}{|c|}{ Liorhysus sp } \\
\hline I & 75 & 30 & 1 & 0 & 1 & 1 & 0 & 0 \\
\hline II & 73 & 27 & 0 & 0 & 0 & 0 & 0 & 0 \\
\hline III & 70 & 33 & 0 & 0 & 0 & 0 & 0 & 0 \\
\hline IV & 70 & 25 & 1 & 0 & 3 & 1 & 0 & 0 \\
\hline $\mathrm{V}$ & 70 & 24 & 0 & 0 & 0 & 0 & 0 & 0 \\
\hline VI & 70 & 16 & 0 & 0 & 0 & 0 & 0 & 0 \\
\hline VII & 70 & 11 & 0 & 0 & 10 & 4 & 0 & 0 \\
\hline total & 498 & 166 & 2 & 0 & 14 & 6 & 0 & 0 \\
\hline $\begin{array}{c}\% \text { de } \\
\text { mortalidad }\end{array}$ & \multicolumn{2}{|c|}{33.33} & \multicolumn{2}{|c|}{0.00} & \multicolumn{2}{|c|}{42.86} & \multicolumn{2}{|c|}{-} \\
\hline
\end{tabular}


En cuanto a la patogenicidad se observa que solo actuó sobre Nysius sp. y no en Liorhysus sp pudiendo deberse a que las poblaciones de Liorhysus sp fueron muy escasas al momento de la aplicación.

Se observa que en estados inmaduros (ninfa) presentan una mayor patogenicidad, ya que, se obtuvo un $42.86 \%$ de mortalidad.

En estado adulto se observa una mayor tolerancia a la infección de Beauveria nativa, obteniéndose el $33.33 \%$ de mortalidad Figura 3 y 4.

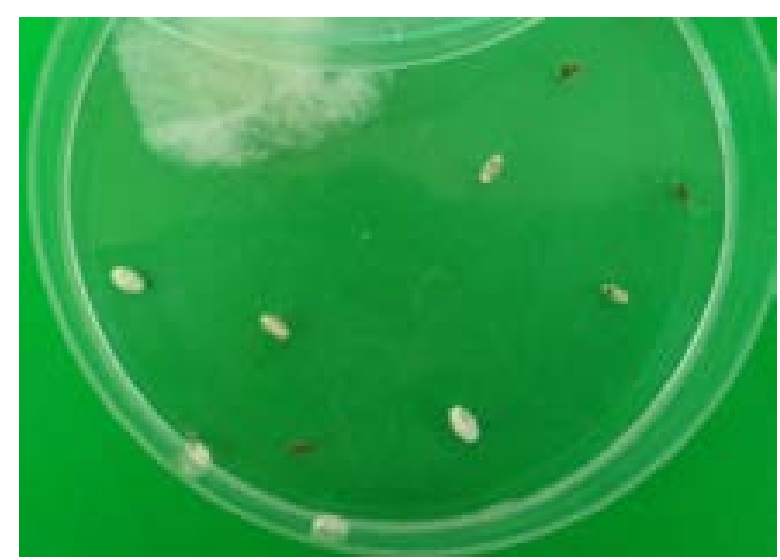

Figura 3: Especímenes infectados por Beauveria bassiana (nativa)

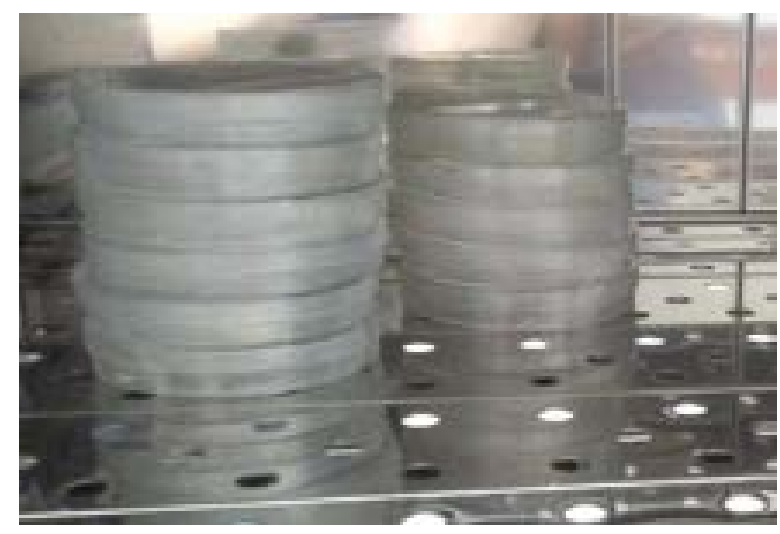

Figura 4: Especímenes recolectados de campo y puestos en cama húmeda

\section{CONCLUSIONES}

- En cuanto a la patogenicidad se observa que solo actuó sobre Nysius sp. y no en Liorhysus sp pudiendo deberse a que las poblaciones de Liorhysus sp fueron muy escasas al momento de la aplicación.

- Se observa que en estados inmaduros (ninfa) presentan una mayor patogenicidad, ya que, se obtuvo un 42.86 $\%$ de mortalidad.

- En estado adulto se observa una mayor tolerancia a la infección de Beauveria nativa, obteniéndose el 33.33\% de mortalidad.

\section{AGRADECIMIENTO}

A la empresa AGROUNIMEX S.A. quienes a través del proyecto "Tecnología para el control eficiente del complejo de Chinches en cultivo de quinua (Chenopodium quinoa) en la Irrigación Majes" según convenio

PITEI-2-P-111-027-14, financio el desarrollo de este trabajo de investigación.

\section{REFERENCIAS BIBLIOGRÁFICAS}

1. Delgado, P. A. M., Murcia-Ordoñez, B. (2011). Hongos entomopatógenos como alternativa para el control biológico de plagas. Disponible en: http://www.redalyc. org/pdf/928/92819767006.pdf

2. El Mercurio disponible en:

3. http://www.elmercurio.com/Campo/Noticias/ Noticias/2014/04/08/Hongos-entomopatogenos-unaalternativa-para-el-control-de-plagas.aspx 